\title{
Economic significance of geotechnical uncertainties in open pit mines
}

\author{
R Jele Evolution Mining Ltd, Australia \\ MJ Dunn Evolution Mining Ltd, Australia
}

\begin{abstract}
The major cost associated with open pit mine operations is waste stripping. While the steepening of slope angles reduces the stripping ratio, and hence operational costs, it also increases the likelihood of failure. Major slope failures incur significant cost elements including clean-up, disruption to mine operation, and damage to mining equipment and in some cases loss of reserves. Geotechnical engineers are often faced with the difficult task of finding the balance between slope optimisation and acceptable risk related to the likelihood of large slope failures. Technological advancements have allowed for the development of larger and deeper open pit operations, but have also created higher economic impact from potential slope failures. Given that the aim of mining operators is to maximise overall profits, it is surprising that most slope designs are based on deterministic design approaches, and limited attention is given to quantifying uncertainties in the geotechnical model. As most major decisions in the mining industry are made by senior management staff and financial staff, any attempt on linking slope stability analysis results with monetary values would improve the critical communication between geotechnical designers and decision-makers.

Using Cowal Gold Mine as a case study, this paper illustrates economic risk caused by geotechnical uncertainties. The geotechnical risk estimate is generally subjective due to geotechnical engineers having to rely on limited data and engineering judgement. Geotechnical risk is compared against economic factors that are often perceived as important variables in mining operations.
\end{abstract}

Keywords: uncertainty, risk

\section{Introduction}

This paper focuses on slope design and the associated geotechnical uncertainties and potential economic impacts that might arise due to slope instabilities. Geotechnical uncertainty has a direct link with slope design reliability, and it is this reliability that has an impact on the economic risk. Ways of reducing uncertainty that may impact on economic risk are briefly outlined, as are slope management issues. The first part of the paper discusses some of the issues related to uncertainty and impacts on slope design, whilst the second part discusses how geotechnical uncertainty is addressed at Cowal Gold Mine (CGM), as well as demonstrating the impact of slope angles on the economics of the pit.

\section{Types of data uncertainty and risk in the operating mining environment}

Mine designs take place in an environment of considerable uncertainty (Bieniawski 1991, 1992). Soil and rock are arguably the most variable of all engineering materials. This variability is usually coupled with paucity of data at local and regional scales. Thus, the conditions in which mining takes place are very variable. MacMahon (1985) and Lilly (2005) provide a very good overview of the various types of uncertainty that need to be considered in geotechnical design. McMahon (1985) outlined six types of uncertainty encountered in geotechnical engineering. The first three types of uncertainty are due to geological or natural constraints. Others are due to social or human nature. Another source of uncertainty, which acts as a counterbalance to the other uncertainties, is the risk of being over-conservative. Over-conservative designs lead to waste of 
resources and, at most, abandonment of mine projects. Lilly (2005) expanded on these and included a seventh uncertainty relating to significant model simplification of the actual situation.

Minimising uncertainty by suitable investigation of conditions will provide an environment in which more-reliable designs can be developed, and hence, either reduce the negative risk (threat), or enable the opportunity risk (and its possible economic effects) to be better quantified.

The sources of uncertainties must first be identified before they can be quantified. Read (2009a) classified data uncertainties in geotechnical engineering into three categories, and these are briefly discussed in the following sections. This is a simplification of the uncertainties described by MacMahon (1995) and Lilly (2005).

\subsection{Geological uncertainty}

Geological uncertainty is associated with geological boundaries, geometry and structures. This includes errors in accurately defining geological features, as well as unforeseen geological conditions.

Attention should be given to the discontinuity network that intersects the rock mass at different scales (Read 2009a). Natural variability of the geometric and mechanical parameters of the discontinuities requires statistical study and, therefore, rigorous implementation of sampling and testing techniques is required. This includes field measurement of discontinuities through systematic mapping of excavated slopes, oriented core; classification of discontinuities in directional sets using stereographic projection techniques or automatic classification statistical analysis of the geometrical parameters of each set using histograms of the principal geometric characteristics of the discontinuities; dip direction, dip angle, persistence or trace length and spacing.

\subsection{Parameter uncertainty}

Parameter uncertainty can otherwise be expressed as how well the data represents the reality. Logger errors and sampling bias are the most obvious errors causing deviation from reality. The sampling bias could be significant if there is no data other than drill core. The continuity of the joints and their large-scale expression are impossible to judge solely from core, leaving a whole range of possibilities for rock mass behaviour. The discontinuities parallel to the core axis are invisible unless holes are oriented in several directions (Lorig 2009).

It is important that all the critical parameters influencing the rock mass behaviour are catered for. Ignoring strength reduction due to microfractures, or ignoring the presence of cemented joints, could lead to more-complex and large failures. Rather than ignoring the issues, it is better to use a simplistic method as it is better to be roughly right than precisely wrong (Jefferies et al. 2008; Hoek 1994).

Human error can also contribute to uncertainty (Read 1994). Errors in observations, testing, communication on the part of geotechnical engineers and errors of understanding and commissioning on the part of the team implementing the design.

In addition to this, mining activities such as blasting induce extra load or inflict damage on the natural materials, which is difficult to predict, and thus adds additional uncertainty to the design process. Uncertainty influences the likelihood of slope instability, which has a material impact on mining economics. 


\subsection{Model uncertainty}

This is related to the unpredictability surrounding the selection of different types of analyses methods used in slope design (Lorig et al. 2009). The analysis of geological structures and geotechnical parameters of the considered material, as well as analysis of mechanical stresses generated by the mining excavation lead to identifying the most critical mechanisms of deformation and failure.

In general, the simplification of these critical mechanisms using homogenisation and generalisation techniques is required to set up physical and then numerical models that allow the quantification of the risk of failure. The effect of such simplification processes inherent to any numerical modelling should not be undervalued and these should thus be used with caution. In each situation, we must be able to estimate the difference between results produced by the model and reality (Swindels 1990).

Very often, a sliding surface (generally convex in shape) follows different sources of weakness within the rock mass, for instance pre-existing discontinuities, stratigraphical joints or in-depth weathered zones. Such polygonal surface is therefore a mixed mode failure in which part of the failure surface is structurally controlled and part is failure through the rock material.

In many cases, the discontinuous nature of the rock mass, as well as the mechanical behaviour of the rock material itself plays an important role in the process of deformation and failure. In this case, especially when large volumes are involved, very complex mechanisms may occur and are difficult to characterise. In such cases, numerical modelling emphasising the discontinuous or continuous aspects of the rock mass allows describing the most likely theoretical process of deformation. The implementation of these models, however, requires a comprehensive knowledge of many mechanical parameters (Hadjigeorgiou \& Harrison 2011). From the earliest stages of the project, monitoring systems and instrumentation must be installed to monitor the behaviour of rocks to make the best use of modelling.

\section{Implications of geotechnical uncertainty}

Unlike in other engineering fields, such as electrical and mechanical, where design requirements, design methods, and design standards are often codified and there is far less variability of the materials being used; mining operations must deal with a highly variable environment and materials. In addition to natural variability, there is often high degree of uncertainty related to geotechnical slope design. Mining operations cannot be too conservatively designed since this will impact negatively on profitability, hence design approaches to reduce risk and ensure safe and effective operation becomes critical.

The lack of quality data and geotechnical models may lead to unreliable slope model inputs and, consequently, inaccurate analyses. In the past, there had been no guidelines as to what constitute an appropriate quality of data. More recently, it has been suggested that the required confidence level for geotechnical data at each project stage should be formerly described Steffen (1997) suggested linking the slope design effort to the mineral resource and ore reserve process. Haile (2004) recommended considering the likely economic impact that data uncertainty is likely to have on project viability. Stacey (2009) also recommendeds using the resource codes as a guide, but suggested that for each project stage, the confidence level for geotechnical data should be the same as the confidence level for mineral resource (Table 1).

Ultimately, slope designs based on unreliable geotechnical models, which have a high degree of uncertainty can have significant economic impacts. This can translate into slope designs that are conservative and do not optimise the open pit extraction or can result in overly aggressive designs resulting in significant failures at inter-ramp or overall scale that incur significant clean-up costs, production disruptions, and delays in realised revenue, and in some cases, the losses of ounces, as well as being a significant safety issue. In the worst cases, a significant failure may bring mining operations to an early end. 
Table 1 Suggested target levels of data confidence by project stage (after Read 2009b)

\begin{tabular}{|c|c|c|c|c|c|}
\hline \multicolumn{6}{|l|}{ Project stage } \\
\hline $\begin{array}{l}\text { Project level } \\
\text { status }\end{array}$ & Conceptual & Pre-feasibility & Feasibility & $\begin{array}{l}\text { Design and } \\
\text { construction }\end{array}$ & Operations \\
\hline $\begin{array}{l}\text { Geotechnical } \\
\text { level status }\end{array}$ & Level 1 & Level 2 & Level 3 & Level 4 & Level 5 \\
\hline $\begin{array}{l}\text { Geotechnical } \\
\text { characterisation }\end{array}$ & $\begin{array}{l}\text { Pertinent } \\
\text { regional } \\
\text { information }\end{array}$ & $\begin{array}{l}\text { Assessment and } \\
\text { compilation of } \\
\text { initial mine-scale } \\
\text { geotechnical } \\
\text { data }\end{array}$ & $\begin{array}{l}\text { Ongoing } \\
\text { assessment and } \\
\text { compilation of all } \\
\text { new mine-scale } \\
\text { geotechnical } \\
\text { data }\end{array}$ & $\begin{array}{l}\text { Refinement of } \\
\text { geotechnical } \\
\text { database and } \\
\text { 3D model }\end{array}$ & $\begin{array}{l}\text { Ongoing } \\
\text { maintenance of } \\
\text { geotechnical } \\
\text { database and } \\
\text { 3D model }\end{array}$ \\
\hline \multicolumn{6}{|c|}{ Target levels of data confidence for each model } \\
\hline Geology & $>50 \%$ & $50-70 \%$ & $65-85 \%$ & $80-90 \%$ & $>90 \%$ \\
\hline Structural & $>20 \%$ & $40-50 \%$ & $45-70 \%$ & $60-75 \%$ & $>75 \%$ \\
\hline Hydrogeological & $>20 \%$ & $30-50 \%$ & $40-65 \%$ & $60-75 \%$ & $>75 \%$ \\
\hline Rock mass & $>30 \%$ & $40-65 \%$ & $60-75 \%$ & $70-80 \%$ & $>80 \%$ \\
\hline Geotechnical & $>30 \%$ & $40-60 \%$ & $50-75 \%$ & $65-85 \%$ & $>80 \%$ \\
\hline
\end{tabular}

\section{$4 \quad$ Accounting for geotechnical uncertainties in pit slope design and mine planning}

The geotechnical model forms the basis of all slope designs. As described in Guest and Read (2009), the geotechnical model is made up of several components, as follows:

- Geological model.

- Structural model.

- Hydrogeological model.

- Rock mass model.

Uncertainties with the geotechnical model will generally transfer through to the slope design. However, the choice of more-conservative acceptance criteria does assist in catering for geotechnical uncertainty. Reducing and understanding uncertainties associated with the geotechnical model will assist in developing more-reliable designs and a better understanding of slope risks.

Stacey (2009), Read (2009c), Dunn $(2014,2015)$ and other authors have outlined the data and design reliability that need to be considered at different stages of the project in developing reliable geotechnical models that have a confidence level and reliability that is commensurate with the required design reliability. The need to understand and quantify geotechnical uncertainty is highlighted.

Geotechnical uncertainty can be dealt with in several ways. The first step is to develop robust geotechnical models following good practices during all stages and this is described by several authors (Dunn 2014, 2015; Hadjigeorgiou \& Harrison 2011; Hadjigeorgiou 2012). The second is to recognise that uncertainty exists, and to include this in the design analyses using probabilistic methods or careful selection of input parameters. The best approach is to combine these two approaches. 
Ideally, mine planning and geotechnical professionals should work closely together to produce the optimal slope design. Hustrulid et al. (2001) observed that there is a tendency for each discipline to specialise in its own area with limited awareness of the needs of other disciplines. He also commented on the limited influence geotechnical professionals may have on final decisions. One of the reasons for this could be the lack of understanding of geotechnical risks and their potential economic impact by other disciplines.

\subsection{Quantifying the economic consequences of slope failure events}

A way to assess the economic and safety risk associated with geotechnical designs is to estimate the impact of slope failures on the efficiency of the operation. To do this, the Probability of Failure (PF) and the consequence of failure need to be estimated. The PF and failure tonnage can be established by examining results from slope stability analyses. It is difficult to predict the consequence of failure as it depends on several factors (Lai et al. 2009). Some of the more important factors are briefly described as follows:

1. Failure tonnage: Higher failure tonnage leads to higher direct cleaning cost. Lilly (2006) suggested applying an efficiency factor of $70-80 \%$ to the normal mining cost due to the challenge in excavating failed material. In addition to this, higher failure tonnage also leads to longer clean-up time, therefore delaying equipment from returning to planned mining activities.

2. Availability of mining equipment for clean-up If mining equipment is running at capacity, they would need to be mobilised from production activities. This will delay the mine's overall production.

3. Location of failure: Slope failures situated close to an operating ramp may cause loss of ramp access and/or damage to nearby mining equipment. Mining operations may also be disrupted leading to sterilised ore. However, if slope failure occurs in an area that does not affect current or planned mining operations, it will incur a much lower cost. The type of slope remediation required varies depending on the location of failure. Furthermore, if failure occurs on top of or within an orebody, it may prevent the ore from being mined.

4. Interim or ultimate slope: Slope failures would disrupt the planned mining sequence of a pit. If a failure event occurred at an interim slope, cleaning up the failed tonnage effectively brings forward material that is intended for mining later, hence causing further disruption to the original mining schedule. If failure occurred at the ultimate slope, failed material is in fact extra unplanned material, increasing the total tonnage of material being mined (Natural Resources Canada 1976).

Call and Kim (1978) and other authors proposed that, once the consequences of slope failure are established, they be incorporated into the mining schedule to simulate the effects of slope failures on project rate of return. As per the following steps:

1. The open pit is divided into several geotechnical domains. Each domain represents sections of the pit that share similar geotechnical properties.

2. Numerical models are employed for slope stability analysis to determine the overall PF of each slope.

3. Based on the risk appetite of the organisation, management chooses the design which suits their risk appetite.

4. The economic consequences of slope failures are then estimated.

5. The effects of slope failures can be incorporated into the mining schedule. This is carried out by applying the Latin hypercube sampling method to simulate slope failures throughout (Lai et al. 2009) the entire mine life and including the failure costs in the mining schedule. The economic returns of the project can then be estimated.

Independent reviews during the design process provides an important control on the quality of the design being undertaken. It is recommended that the reviews be done at completion of the design stage, such that if any shortcomings are identified in the design, it will be necessary to loop back to an earlier step in the process and reassess the design. 


\section{$5 \quad$ Relationship between safety risk and economic risk in open pit mines}

Due to uncertainties in geotechnical materials, potential local and larger slope instabilities need to be managed through the design. Safety risk can be managed through engineering and procedural controls, and effective slope management practices. It is unrealistic to eliminate safety and economic risks totally. The key is to implement engineering designs with a risk profile that is considered acceptable to the owners, regulators and society.

Geotechnical engineering designs have traditionally been largely focused on safety aspects. However, it is important to consider both safety and economic risk aspects. In mining, where the aim is to maximise profit, economics becomes an important consideration. Managing the safety aspects of slope designs has economic implications. Failure to do so can lead to reputational damage, legal action and in the most severe cases, the loss of the licence to operate.

\section{Quantifying the economic effects of geotechnical risk: examples from Cowal Gold Mine}

\subsection{Site description}

CGM is owned by Evolution Mining Limited (Pty). It is $350 \mathrm{~km}$ west of Sydney, Australia and $40 \mathrm{~km}$ northeast of West Wyalong, located on the traditional lands of the Wiradjuri people. CGM is an open pit mining operation with production from several mining faces within a single pit. The pit has been mined in several stages or cutbacks, currently mining is being undertaken in Stage $\mathrm{G}$ and the Stage $\mathrm{H}$ cutback has commenced.

Mining is carried out with a company-owned fleet of mining equipment. Pit benches are $9 \mathrm{~m}$ in height and mined in three $3 \mathrm{~m}$ flitches. Double and triple bench configurations are applied. Ore is hauled by truck from the pit face to either a stockpile area or directly fed into the primary crusher.

\subsection{Slope designs and economic impacts}

The determination of acceptable slope angles is a key aspect in open pit mining as it implies having an optimum balance between additional economic benefits gained from steeper slopes and the risks associated with potential slope instability.

The difficulty in determining the acceptable slope angle is related to geological and parameter uncertainties within the rock mass. These uncertainties are accounted for to some extent in the slope design process through the development of appropriate geotechnical models and approach design processes. Slope angles are only one component of the open pit mine design. However, geotechnical uncertainties impacting on the pit design and economics warrant greater attention from geotechnical practitioners in communication with mine planners.

\subsubsection{Sensitivity analysis results}

Sensitivity analysis is generally performed to examine how different factors affect the financial output of different open pit designs. In this paper, sensitivity analyses were carried out on gold price, slope angles, mining cost and processing cost to assess their impact on the undiscounted cash flow (UCF) and recovered gold.

For CGM, the base case was an inter-ramp angle of $61^{\circ}$, the sensitivity analysis was used to determine the slope design that would result in a balance in terms of volatility in delivering ore to the processing plant and cost. Further scenario analysis showed that with sound implementation of the design, there could be additional benefits in steepening the slope angles. A significant factor will be the ability to achieve the required minimum catch berm widths and manage rockfall hazards. 
The results of the economic sensitivity analysis are shown in Figures 1 and 2 . They show the influence of the financial drivers over the project rate of return. By varying various parameters, it is possible to assess the impact on project economics. Slope angles have a significant impact on UCF and recovered gold. However, this analysis does not capture the differences in potential for slope instabilities between flatter and steeper designs.

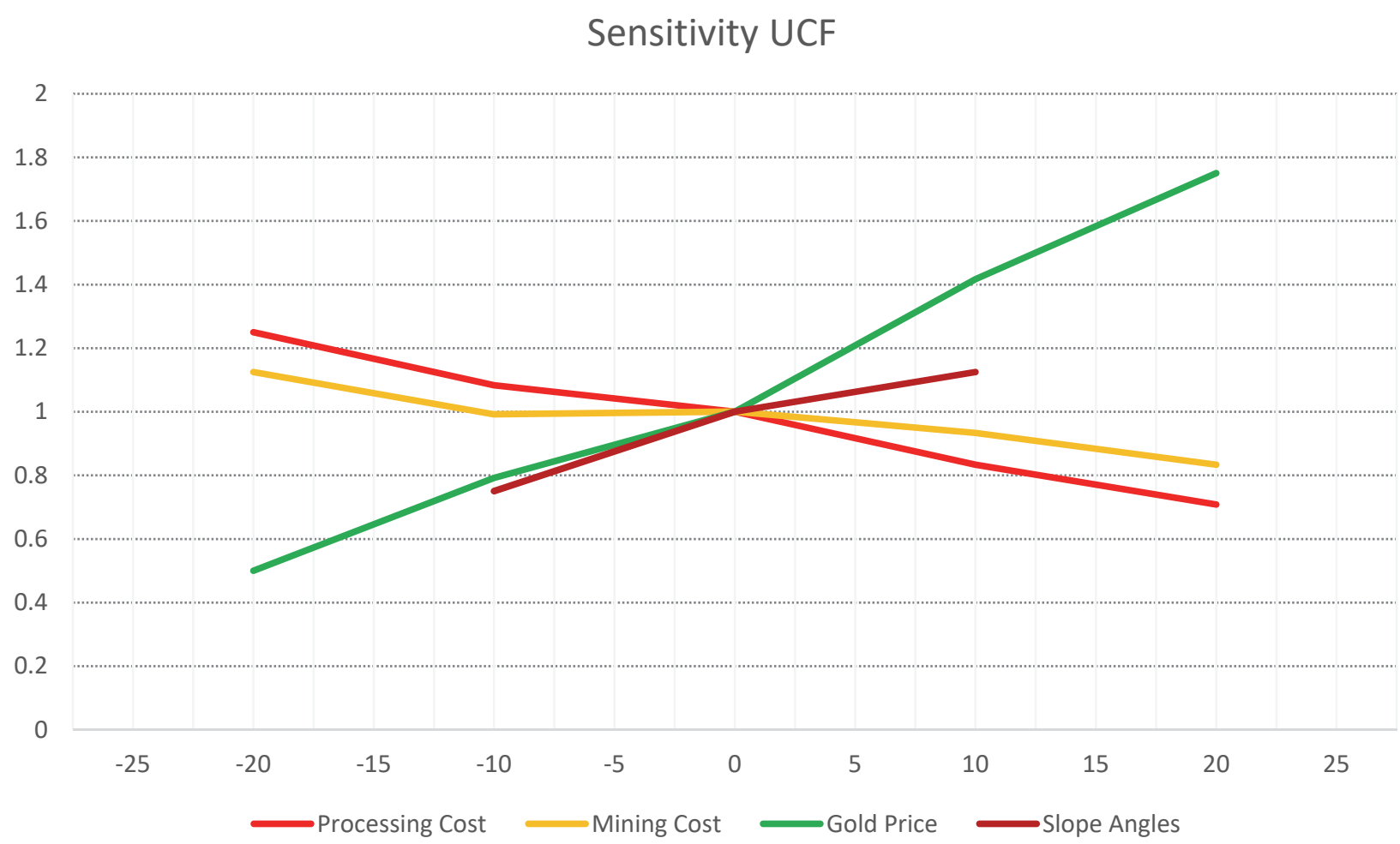

Figure 1 Standard sensitivity variables - UCF

\section{Sensitivity - In situ Gold}

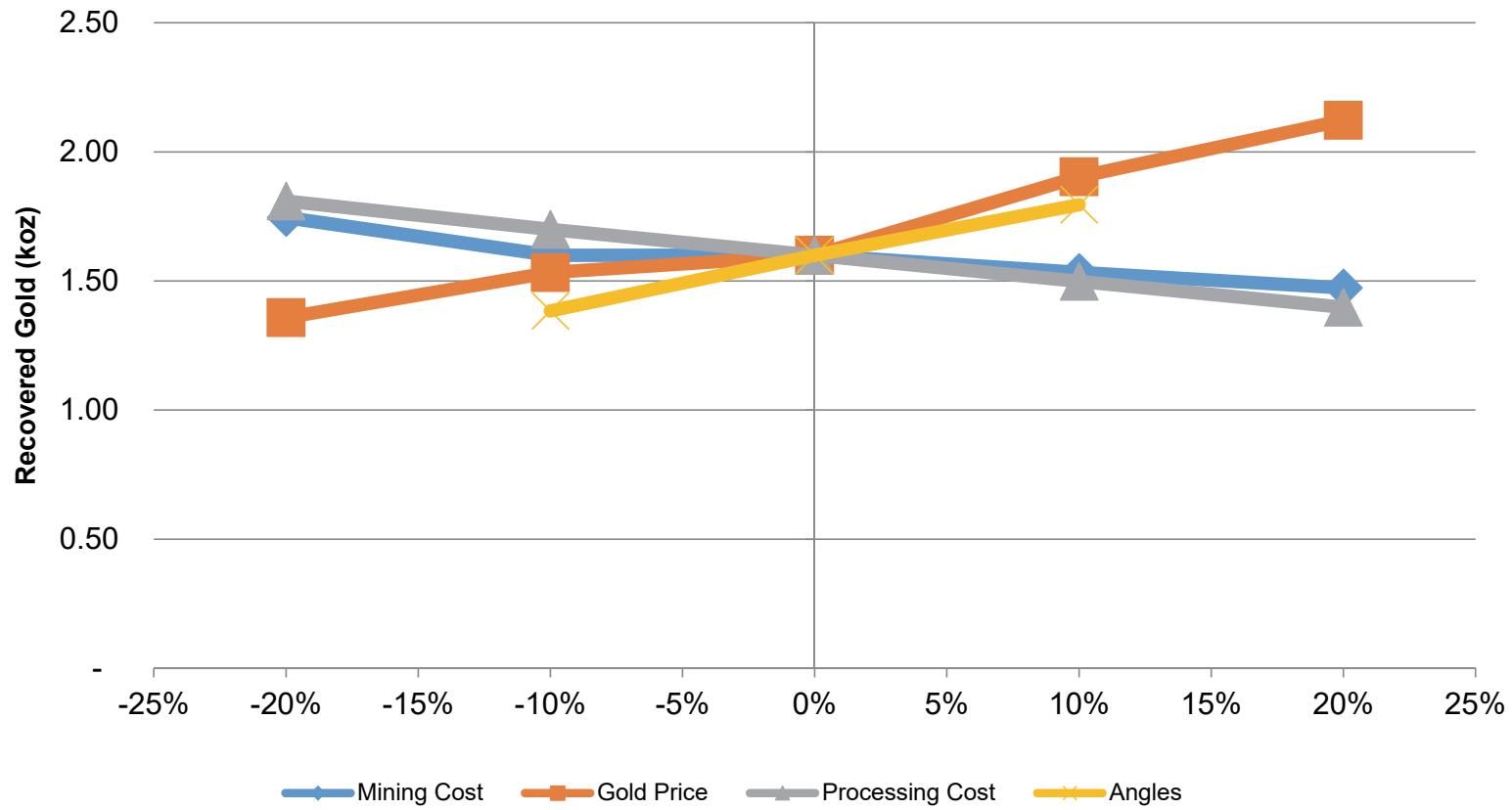

Figure 2 Standard sensitivity variables - in situ gold 
These sensitivity results show that the pit content is sensitive to the pit wall angles. A decrease in wall angles by $10 \%$ creates no mineable shell, which indicates that reduced pit wall angles will render the proposed cutback uneconomic. An increase in the gold price of up to $20 \%$ can have quite large consequences to the pit size and recovered gold in each pit shell.

\subsection{Accounting for geotechnical uncertainty at CGM}

Geotechnical uncertainty and its impact on the reliability of geotechnical models and slope design has been recognised at CGM. The approach utilised to minimising uncertainty has included a focus on developing comprehensive and robust geotechnical models as well as comprehensive monitoring programs. The geotechnical model components are brought together using three-dimensional numerical models that have been correlated against wall monitoring. Implementation and risk management is supported by a comprehensive slope management program and ground control management plan.

\subsection{Geotechnical model}

A brief description of the CGM geotechnical model and various components is provided in the following sections.

\subsubsection{Geotechnical data}

Data collected from mapping, exploration core, and geotechnical drilling is incorporated into a database and is used to develop various components of the geological model. This allowed for the geological boundaries near the surface of the mine to be modelled with a reasonable level of confidence. In contrast, information at greater depths is of less certainty as it is mainly interpolated from the collected data. Figure 3 shows the drillhole coverage at CGM, and Figure 4 shows a geological cross-section through the pit.

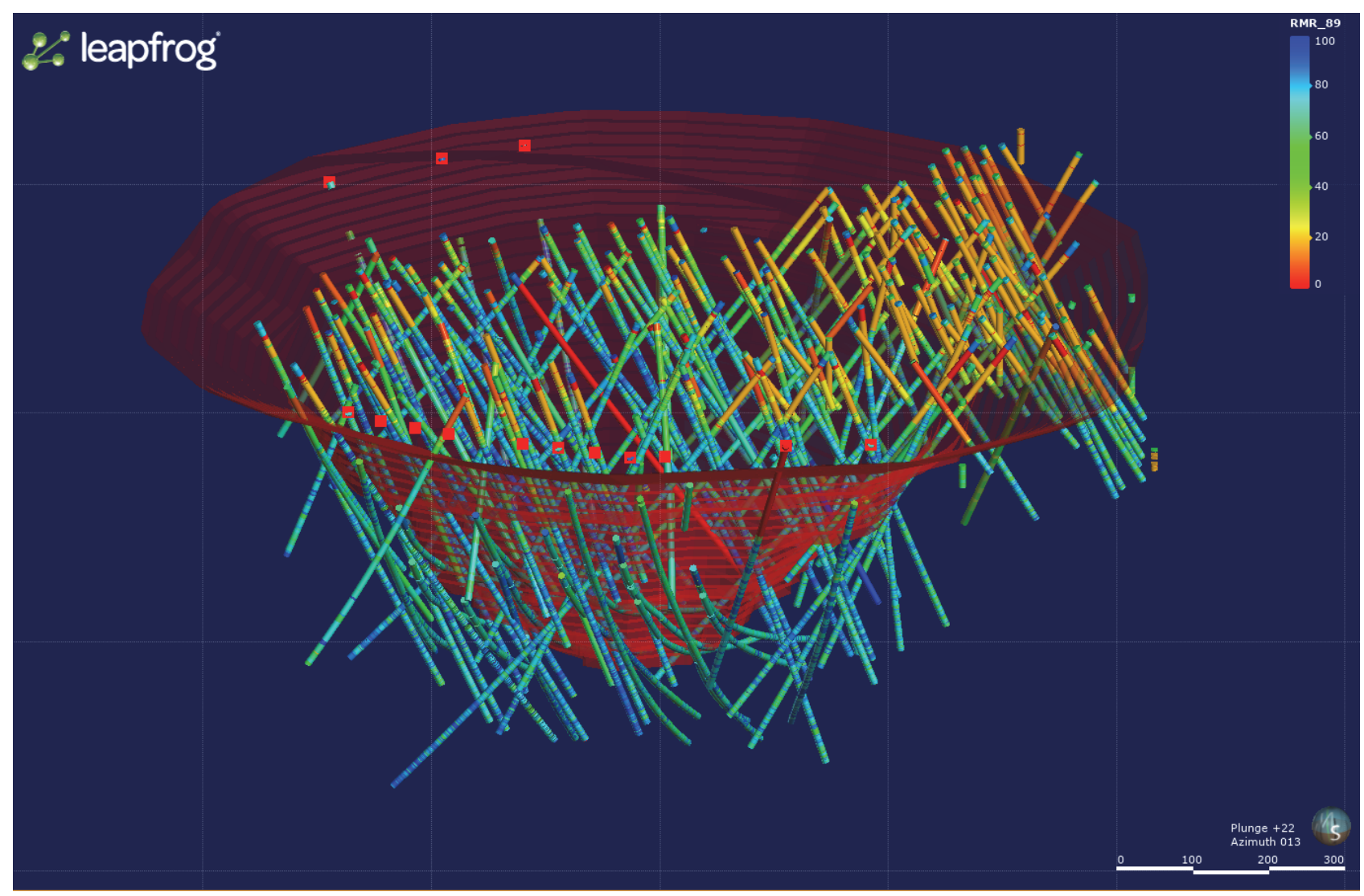

Figure 3 Plan of cored boreholes used to develop the geotechnical model (north is into the page) 


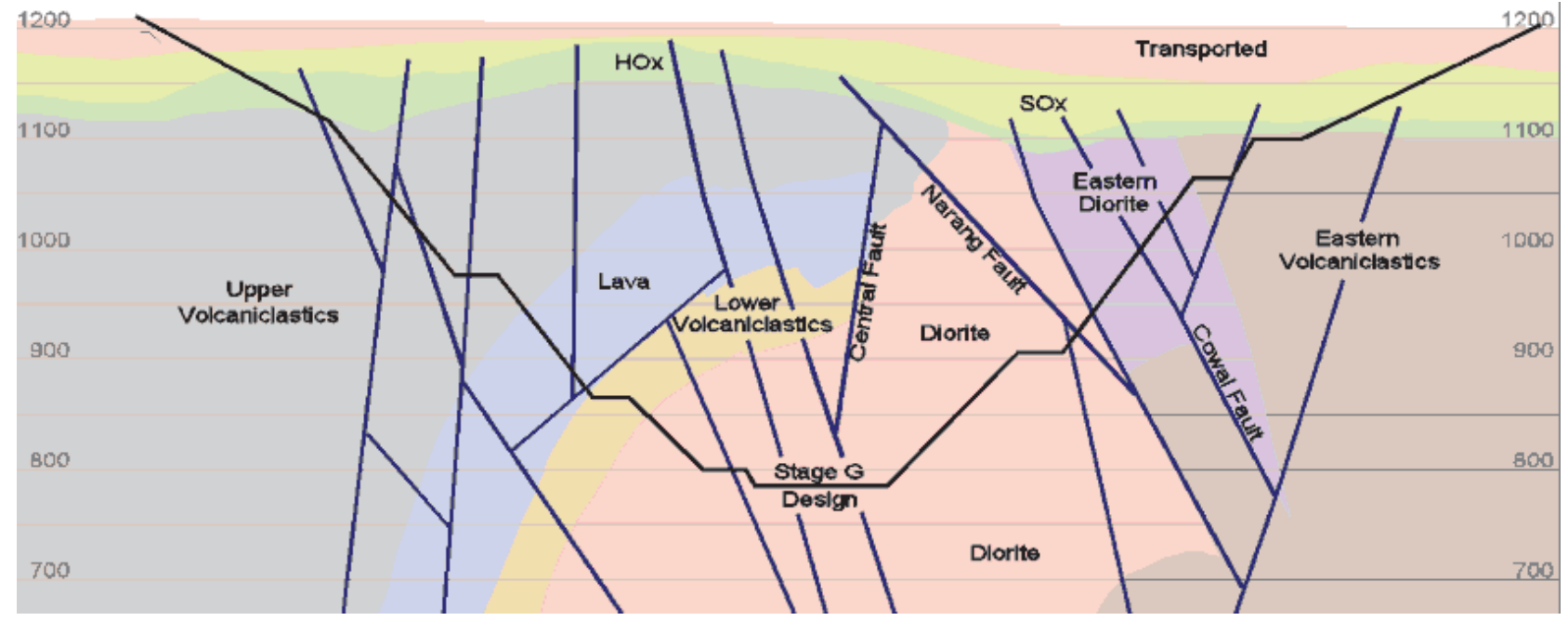

Figure 4 West-east section showing modelled geology and major structures

\subsubsection{Structural model}

At CGM, slope instabilities with the fresh primary rocks are controlled by, or associated with, distinct geological structures; generally the weakest part of the rock mass. Therefore, a detailed knowledge of geological structures may improve our capacity to understand failure mechanisms and prevent potential rockfalls. For CGM, the geological structures are divided into two groups:

- Major structures including shear zones, and fault zones (mine region zone). As the major structures are continuous and widely spaced, they only affect the inter-ramp and overall slopes, as evidenced by previous failures.

- Minor structures including joints and bedding planes (local area of the mine-scale). The minor structural fabrics (shorter length and closely spaced) mainly impact inter-ramp and bench slopes.

The CGM structural database is made up of structural data collected through:

- Core logging.

- Face mapping.

- Photogrammetry mapping.

This data is used to develop the structural model using software such as Leapfrog (ARANZ Geo Ltd 2016). The models are regularly updated, and comparisons are carried out on the updated faults to compare them to the older fault models. Models are also verified in the field.

\subsubsection{Geology model}

The geological model for Cowal was created using the drill core database, which contains records from drilling programs spanning several decades as well as mapping. The units were modelled and interpreted using Leapfrog (ARANZ Geo Ltd 2016).

Geological interpretations are based on a combination of data and pit mapping by the mine geologists. The assessment of uncertainties of the geology model is performed after the modelling is complete. The geological model comprises a network of bench plans and cross-sections (profiles) with geological interpretations, layers and layer boundaries applied to each profile. A qualitative assessment of the uncertainty of the geological interpretation is performed along each profile. 
The geological and structural models are updated as new mapping data is acquired from exposed faces as a way of improving reliability. The geological units along with structural model overlain on the Stage $\mathrm{H}$ design are shown in Figure 5. The approved models are signed off by the geology section and released so that only approved models are used by all team members.

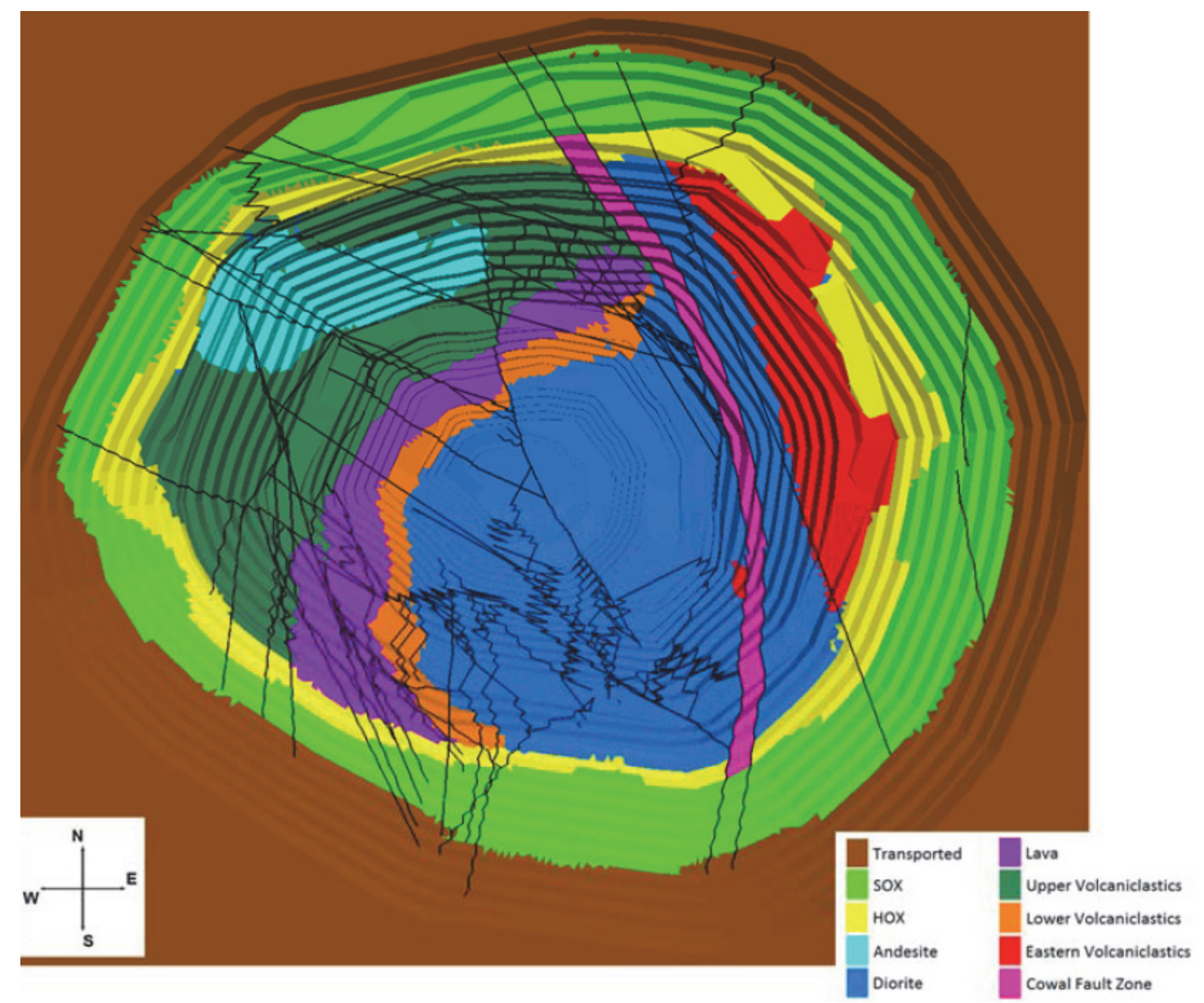

Figure 5 Plan showing exposed soil and rock mass domains and intersected structures in the CGM pit

\subsubsection{Hydrogeological model}

A mature groundwater system encompasses the CGM pit, which has depressurised in response to the mining of the surficial units and the deeper primary materials. Groundwater flow is highest within the lower surficial units. Groundwater has had a significant impact on stability in the transported (lake sediments) and soft oxides (saprolite) materials (Crouse \& Wright 2015). As a result, significant effort has gone into developing a robust hydrogeological model as well as to determine depressurisation requirements for the transported and saprolite materials.

The hydrogeological database has been developed and maintained for many years with significant data input and output upgrades undertaken to improve reporting functionality. The following data is used:

- A comprehensive completion record of as-built and geological intersections for depressurisation holes/wells and piezometers.

- Vibrating wire piezometer (VWP) monitoring array across the open pit.

- Record of horizontal drain completions, inclusive of locations, orientation and depth.

- Historical standpipe data.

- Historical pumping data from sumps and production bores.

- Flow observations from horizontal drains. 
Figure 6 shows the piezometer network around the CGM pit. This coverage has been expanded to cover Stage $\mathrm{H}$ and replace Stage $\mathrm{G}$ piezometers lost due to mining activities.

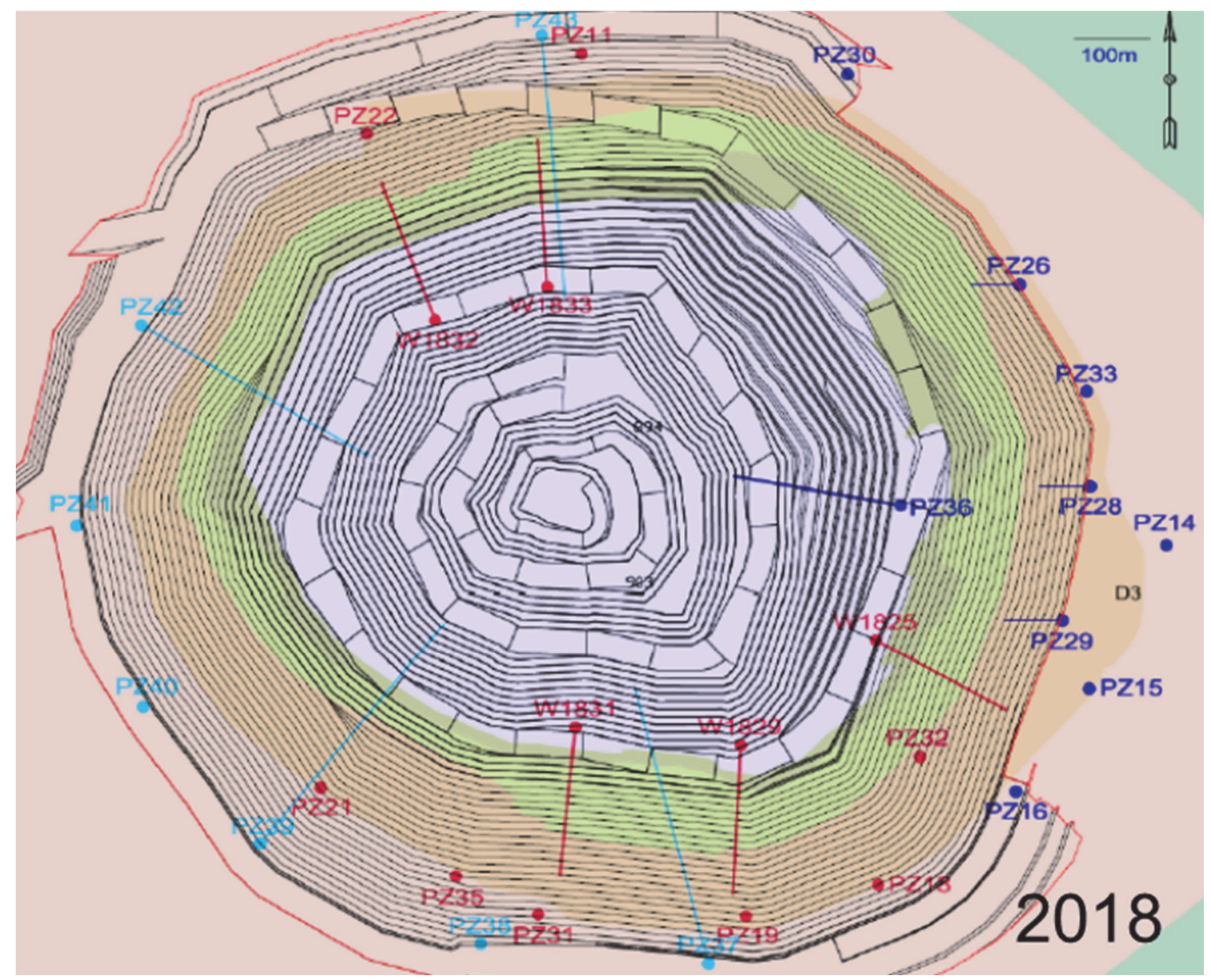

Figure 6 CGM open pit piezometer locations (blue - Stage H Pit VWPs, red - Stage G Pit VWPs)

Good quality hydrogeological data has been used to develop a hydrogeological model that is used to develop the wall depressurisation program. This model has been verified against the monitoring data and is updated using the monitoring data and measured response to open pit mining. The model has been updated prior to finalising the design of each mining stage and is used as an input into three-dimensional stability analyses. Figure 7 shows pore pressures across a section of the pit. The model is also verified during the mining stage to determine if the measured response is as predicted by the hydrogeological model.

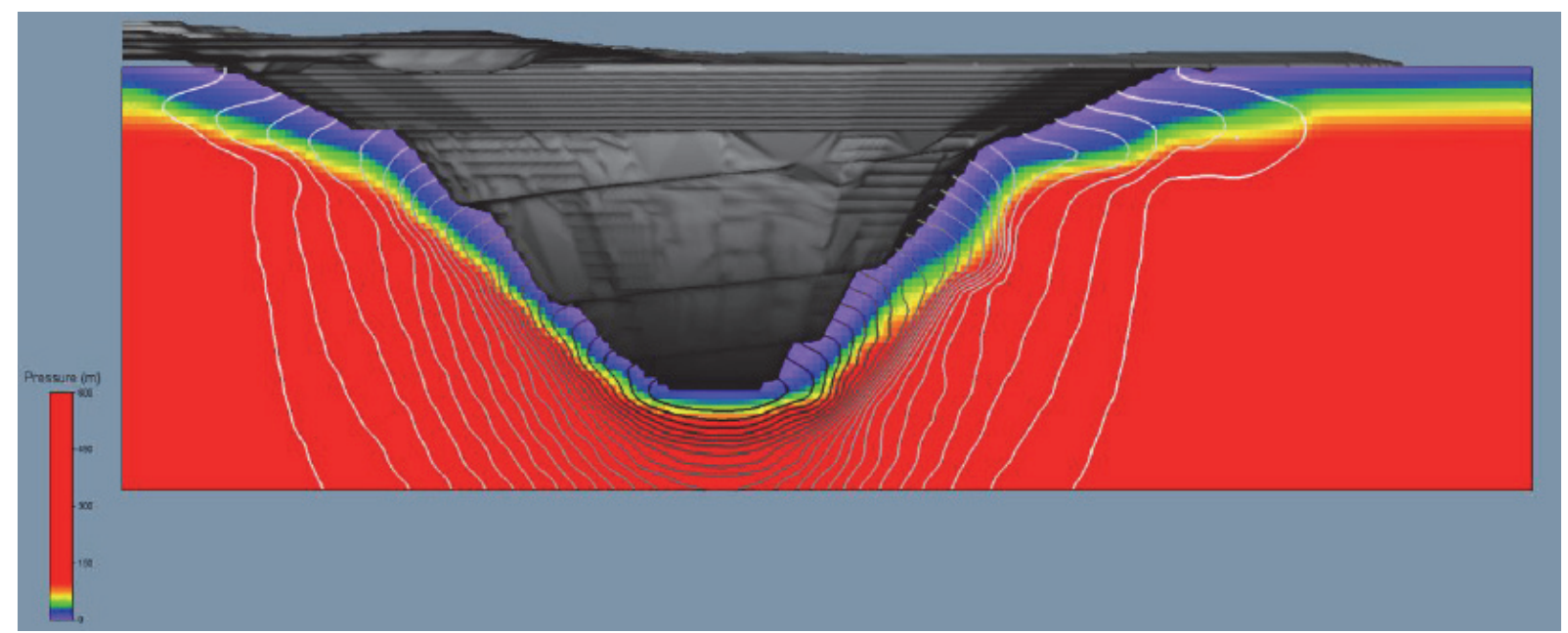

Figure 7 CGM hydrogeological model showing ore pressures 


\subsubsection{Rock mass model}

The rock mass model consists of logging data (rock quality designation, rock mass rating, etc.) laboratory testing data and face mapping data which is also used to validate the drill core data interpretations. These are used to derive input parameters for design analysis. Back-analysis of circular failures (restricted to the transported and saprolite materials) has been used to develop strength parameters for these materials. Back-analysis has also been undertaken of structurally controlled instabilities in the primary rock to understand the shear strength of discontinuities.

Laboratory testing has been undertaken on surficial and primary materials over several campaigns going back to the original pre-feasibility and feasibility design studies as well as later slope steepening studies. This data is maintained in a database.

Geotechnical logging and laboratory testing data have been combined to develop rock mass strength parameters summarised in Table 2. Different disturbance (D) values are used to reflect the impacts of blasting and excavation. These parameters have been verified during several slope design studies and through correlation of the three-dimensional numerical modelling with observed displacements (Crouse \& Wines 2016).

Table 2 CGM rock mass properties

\begin{tabular}{|c|c|c|c|c|c|c|c|c|c|}
\hline $\begin{array}{l}\text { Geotechnical } \\
\text { domain }\end{array}$ & $\begin{array}{l}\rho \\
\left(t / m^{3}\right)\end{array}$ & $\begin{array}{l}E_{i} \\
(G P a)\end{array}$ & $\begin{array}{l}\text { UCS } \\
\text { (MPa) }\end{array}$ & GSI & mi & D & $\begin{array}{l}\sigma_{\mathrm{t}} \\
(\mathrm{MPa})\end{array}$ & $\begin{array}{l}E_{\mathrm{rm}} \\
\text { (GPa) }\end{array}$ & $v$ \\
\hline Hard oxide & 2.00 & 67 & 127 & 34 & 14 & 1.0 & 0.017 & 3.62 & 0.27 \\
\hline Andesite & 2.77 & 65 & 125 & 73 & 21 & $\begin{array}{l}0.7 \\
1.0\end{array}$ & $\begin{array}{l}0.524 \\
0.455\end{array}$ & $\begin{array}{l}24.82 \\
16.08\end{array}$ & 0.21 \\
\hline Diorite & 2.80 & 70 & 132 & 75 & 24 & $\begin{array}{l}0.7 \\
1.0\end{array}$ & $\begin{array}{l}0.580 \\
0.509\end{array}$ & $\begin{array}{l}28.74 \\
18.90\end{array}$ & 0.21 \\
\hline Lava & 2.76 & 70 & 159 & 74 & 22 & $\begin{array}{l}0.7 \\
1.0\end{array}$ & $\begin{array}{l}0.697 \\
0.608\end{array}$ & $\begin{array}{l}27.74 \\
18.11\end{array}$ & 0.21 \\
\hline $\begin{array}{l}\text { Upper } \\
\text { volcaniclastics }\end{array}$ & 2.77 & 67 & 127 & 74 & 14 & $\begin{array}{l}0.7 \\
1.0\end{array}$ & $\begin{array}{l}0.874 \\
0.763\end{array}$ & $\begin{array}{l}26.55 \\
17.33\end{array}$ & 0.21 \\
\hline $\begin{array}{l}\text { Lower } \\
\text { volcaniclastics }\end{array}$ & 2.77 & 67 & 127 & 75 & 14 & $\begin{array}{l}0.7 \\
1.0\end{array}$ & $\begin{array}{l}0.957 \\
0.839\end{array}$ & $\begin{array}{l}27.51 \\
18.09\end{array}$ & 0.21 \\
\hline $\begin{array}{l}\text { Eastern } \\
\text { volcaniclastics }\end{array}$ & 2.77 & 67 & 127 & 66 & 14 & $\begin{array}{l}0.7 \\
1.0\end{array}$ & $\begin{array}{l}0.426 \\
0.356\end{array}$ & $\begin{array}{l}18.72 \\
11.60\end{array}$ & 0.22 \\
\hline & 2.80 & 70 & 132 & 25 & 24 & $\begin{array}{l}0.7 \\
1.0\end{array}$ & $\begin{array}{l}0.006 \\
0.004\end{array}$ & $\begin{array}{l}2.12 \\
1.77\end{array}$ & 0.28 \\
\hline $\begin{array}{l}\text { Cowal fault } \\
\text { zone }\end{array}$ & 2.80 & 70 & 132 & 40 & 24 & $\begin{array}{l}0.5 \\
0.7 \\
1.0\end{array}$ & $\begin{array}{l}0.032 \\
0.025 \\
0.018\end{array}$ & $\begin{array}{r}5.38 \\
4.08 \\
2.79\end{array}$ & 0.26 \\
\hline
\end{tabular}

Notes: $\rho$ - density; $\sigma_{t}$ - tensile strength; $v$ - Poisson's ratio; $\mathrm{mi}$ - Hoek-Brown material constant; $\mathrm{E}_{\mathrm{i}}-$ Young's modulus of intact rock; UCS - uniaxial compressive strength; GSI - geological strength index; D - Hoek-Brown disturbance factor; Erm - Young's modulus of rock mass.

The primary rocks are treated as generalised Hoek-Brown materials, whilst the transported and saprolite materials are treated as Mohr-Coulomb materials, and the shear strength parameters are derived from consolidated undrained triaxial testing and back-analysis of previous instabilities. 


\subsection{Geotechnical domains}

For the CGM open pit, the slope stability in the primary rocks is governed by the structures at various scales. Twenty-five large-scale faults have been explicitly defined as has the rock mass fabric and smaller-scale structures. In the surficial units, failure through the soil/rock mass is the dominant mechanism. The pit is divided into 10 geotechnical domains based on distribution of the major lithological units. As the major structures are continuous and widely spaced, they only affect the inter-ramp and overall slopes. The minor structural fabrics (shorter length and closely spaced) mainly impact inter-ramp and bench slopes. Figure 5 shows exposed soil and rock mass domains and intersected structures in the CGM open pit.

\subsection{Design analysis}

A range of design analyses were undertaken. The design works involved kinematic analysis to identify potential bench and intermediate-scale failures. The structures were filtered using discontinuity lengths to estimate the size of potential instabilities. A discrete fracture network (DFN) model has been developed for the south wall, which highlighted areas with potential unstable blocks. This has been used in some analyses.

FLAC3D (Itasca International, Inc. 2019a) and 3DEC (Itasca International, Inc. 2019b) numerical modelling were undertaken for the oxides/weathered and primary rocks respectively to assess the potential for inter-ramp and overall instability. Three-dimensional modelling is used as it can capture the pit geometry as well as the complex interactions between geological units and structures. The numerical modelling was undertaken to identify areas where instability was likely to develop during the mining phase; an example being the multi bench wedge instability of the southwest wall, which will be discussed. The DFN and major structures were included in some of these models.

\subsubsection{Stage $\mathrm{G}$ switchback design modification}

Given that it is not possible to account for all geological uncertainties, it is necessary to maintain a degree of flexibility and to modify slope designs when unexpected geological conditions are intersected. A design modification was undertaken to minimise potential impact of identified wedge instability on the south wall above the planned ramp. The instability necessitated that the ramp be switched back at the $912 \mathrm{mRL}$ to run along the east wall towards the north, instead of running along the south wall. The initial design included a single ramp running from the pit base in a clockwise direction with no switchbacks. Figure 8 shows the two design scenarios.

stage_g_20160511_geotechbw.str

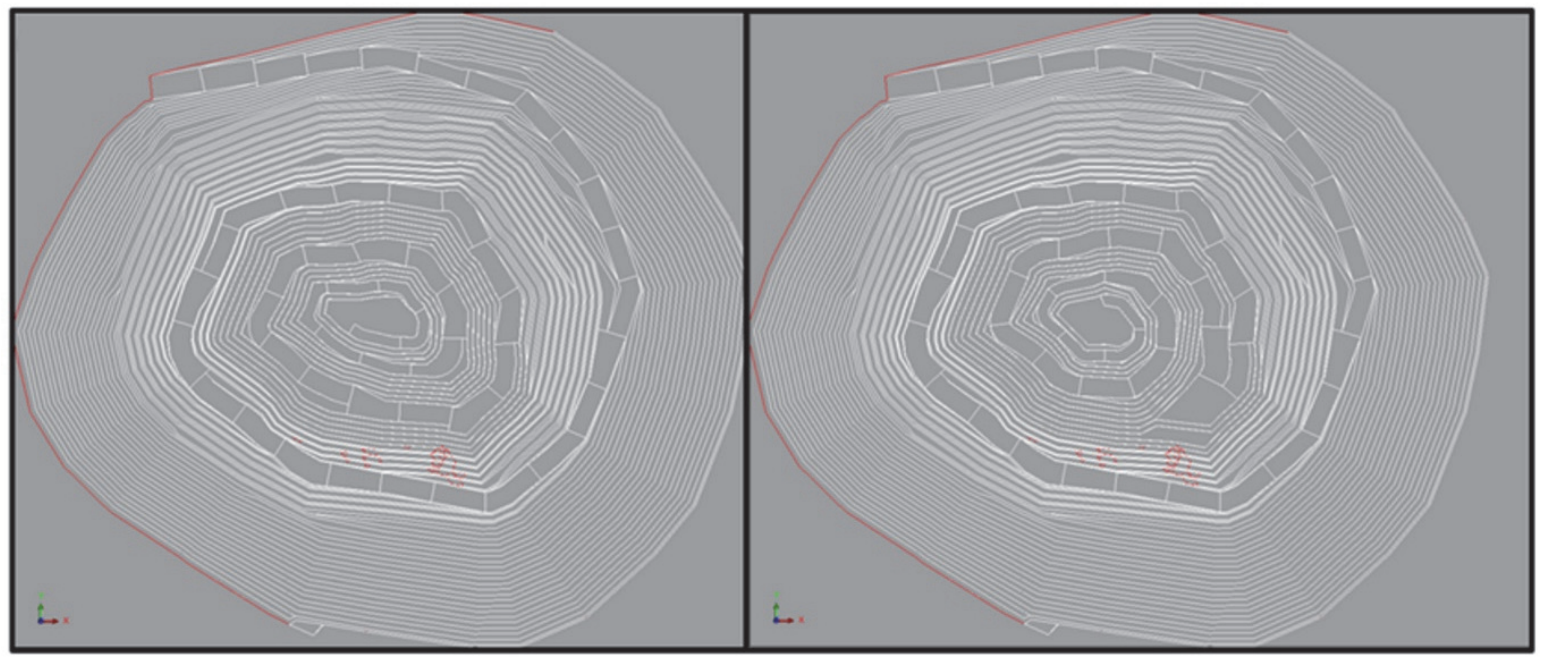

(a)

\section{stage_g_20161011_sback.str}

(b)

Figure 8 (a) Scenario A with ramp running along east wall; (b) Scenario B with switchback. Red - identified potential wedges 
At CGM, the implementation of designs allows for flexibility to deal with problems that may arise during the mining process. Geotechnical stability analysis was performed on the proposed Stage G switchback and below is a summary of the analysis as follows:

- All failure mechanisms identified by the modelling are structurally controlled, and most of these potential failures occur on the south wall.

- For the models with the base case fault properties, no failures are predicted after Stage $G$ excavation that would cause loss of the ramp (due to the ramp itself failing). However, rockfalls could land on the ramp, particularly where it passes below the south wall.

- A potential failure is identified between the Fault 5 and Fault 7 structures in the lower south wall. This failure could result in partial loss of the ramp where it passes around the south wall. The likelihood of this failure occurring will depend on the exact location of these structures in the lower slope. The modelling indicates that reducing the pore pressures would increase stability for this potential wedge (Figure 9).

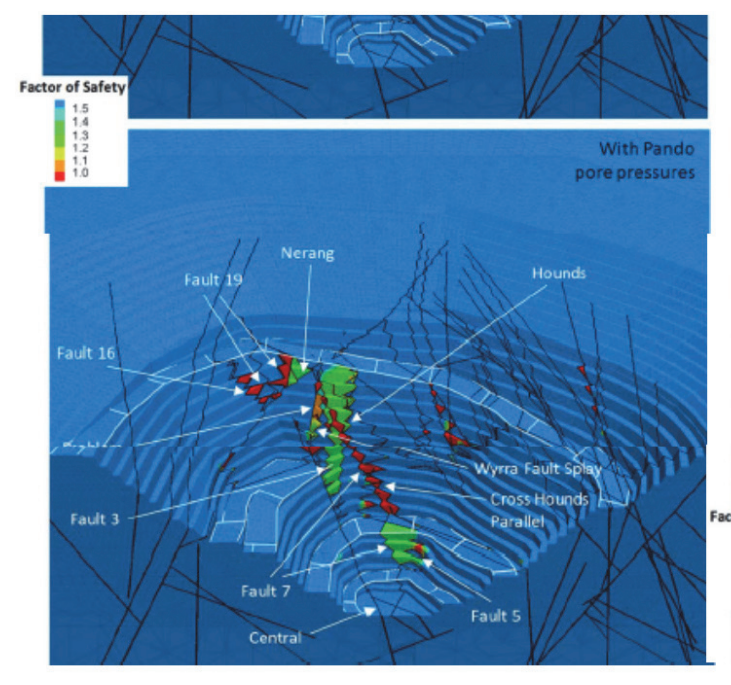

(a)

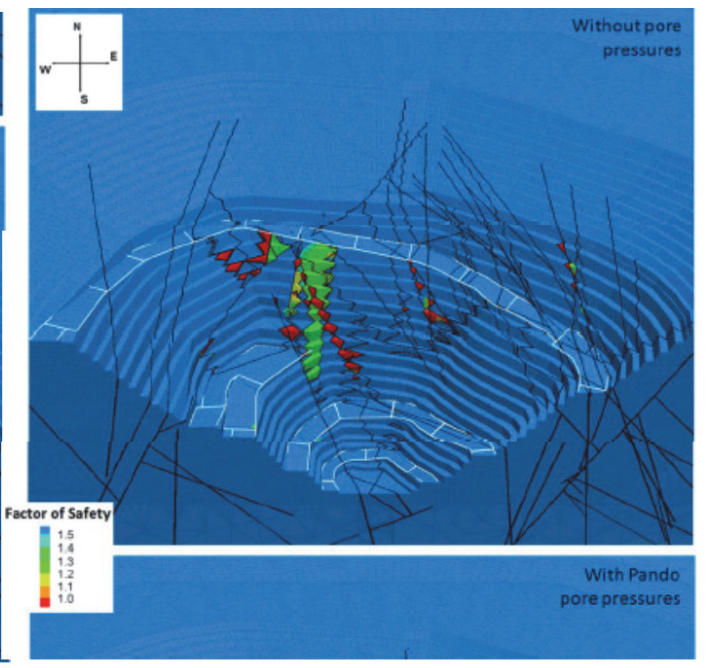

(b)

Figure 9 (a) Factor of Safety (FS) after Stage G excavation with lower bound fault properties and no pore pressures; (b) FS after Stage G excavation with lower bound fault properties and no pore pressures

A comparison of the designs shows that $65.8 \mathrm{koz}$ of ore at a cutoff grade of $0.4 \mathrm{~g} / \mathrm{t}$ has been deferred into Stage $\mathrm{H}$ with the inclusion of the switchback. The number of differed ounces is equivalent to three months' production target. In addition, the width between the Stage $\mathrm{G}$ and Stage $\mathrm{H}$ designs has been decreased on the $876 \mathrm{mRL}$ to $23 \mathrm{~m}$. A decrease in the Stage $\mathrm{H}$ ramp width can increase the mining width (current Stage $\mathrm{H}$ ramp width on $876 \mathrm{mRL}$ is $40 \mathrm{~m}$ ). This applies for the $867 \mathrm{mRL}$ as well.

Implementation of the switchback allowed for a step in below the identified wedge, increasing catch capacity in case the wedge failure eventuates. This course of action improved the reliability of the Stage $\mathrm{G}$ mine plan going forward and only resulted in deferred ounces which were a modest proportion the Stage $G$ mining phase.

\subsection{Slope management: operational measures}

A comprehensive pit slope management program embodied in the ground control management plan (GCMP) is an effective way in which to manage geotechnical risks associated with open pit mining. Where these programs are comprehensive and subject to regular critical review, they can be effective and sufficient to manage geotechnical hazards. 
The slope management program implemented at CGM is a risk-based approach centred on the assessment of geotechnical hazards and risk.

This slope management program provides a systematic framework to ensure that potential geotechnical hazards and risks are identified early and thoroughly evaluated to allow effective controls to be identified and implemented. The slope design and as-built slope potential risks are assessed and managed through a slope monitoring program. This process is used to manage uncertainties not identified and catered for during the slope design and mine planning phases.

The slope management program is used to assess pre- and post-control risk for current and future potential risks, and geotechnical hazards (realised risks). This system utilises the Evolution Mining risk matrix, but also introduces the important 'temporal' exposure element critical to geotechnical risk assessment.

\section{Discussion}

The potential impact of geotechnical uncertainties has been recognised at CGM and this is addressed by developing comprehensive and robust geotechnical models and undertaking an appropriate design analysis that captures the three-dimensional failure mechanisms.

Financial sensitivity analyses have demonstrated the impact of slope angles on financial outcomes both in terms of achieving flatter overall slope angles due to geotechnical issues or implementing steeper slopes. In the case of steeper slope angles, there may be an increase in the PF. Both failure to achieve design slope angles or potential upside, albeit at a higher risk, impact on geotechnical uncertainties.

Not all uncertainties can be catered for, and geotechnical issues will arise. The safety risks can be managed through an effective and comprehensive GCMP, whilst flexibility is needed to address and manage business risk. This was demonstrated through the Stage $\mathrm{G}$ switchback design modification example. This highlights the need for effective communication between geotechnical engineers and the mine planners, and an integrated approach. The communication of geotechnical uncertainties and associated risks to mine planners and senior management is an area that can be improved in the geotechnical discipline and should be a focus area across the industry.

\section{Conclusion}

As stated in Read (1994), geotechnical risk in the form of unexpected geological conditions has a significant implication on cost and schedule control in mining operations. The best course of action is to define the geological uncertainties early and as accurately as possible to minimise the risk. This should form part of the elements considered in decision-making.

An increasing number of risk sources are being quantified in monetary terms in the mining industry. While the variable nature of rock and soil makes it difficult to place a dollar value on risk, it is important that geotechnical engineering does not fall behind in interpreting risk in monetary terms. Geotechnical professionals should improve the way in which geotechnical uncertainty and associated risks are communicated to various stakeholders.

This paper demonstrates how CGM manages geotechnical uncertainty through the development of robust geotechnical models, use of appropriate design methods, and effective management of slopes through the GCMP and risk assessment tools.

It was also demonstrated that geotechnical issues do arise and that design modifications may be required. Effective communication and integration between the various stakeholders is needed to manage both safety and business risks. 


\section{References}

ARANZ Geo Ltd 2016, Leapfrog, computer software, ARANZ Geo Ltd, Christchurch, http://www.leapfrog3d.com/products/leapfrog-geo Bieniawski, ZT 1991, 'In search of a design methodology for rock mechanics', in Roegiers (ed.), Proceedings of the 32rd US Symposium on Rock Mechanics, A.A. Balkema, Rotterdam, pp. 1027-1036.

Bieniawski, ZT 1992, 'Principles of engineering design for rock mechanics', in JR Tillerson and WR Wawersik (eds), Proceedings of the 33rd US Symposium on Rock Mechanics, A.A. Balkema, Rotterdam, pp. 1031-1040.

Call, RD, \& Kim, YC 1978, 'Composite probability of instability for optimizing pit slope design', in YC Kim (ed.), Proceedings of the 19th US Symposium on Rock Mechanics, American Rock Mechanics Association, Alexandria.

Crouse, RL \& Wines, DR 2016, 'Cowal gold mine - documentation of slope deformations due to mining to final pit walls - a case history', in PM Dight (ed.), Proceedings of the First Asia Pacific Slope Stability in Mining Conference, Australian Centre for Geomechanics, Perth, pp. 107-126.

Crouse, R \& Wright, S 2015, 'Cowal gold mine: success in mining through saprolites - a case history', Mining Engineering, September 2015, http://me.smenet.org/docs/Publications/ME/Issue/Cowal_Final.pdf

Dunn, MJ 2014, 'Geotechnical models and data confidence in mining geotechnical design', Proceedings of the Third Australasian Ground Control in Mining Conference, The Australasian Institute of Mining and Metallurgy, Melbourne, pp. 105-112.

Dunn, MJ 2015, 'How reliable are your design inputs?', in Y Potvin (ed.), Proceeding of the International Seminar on Design Methods in Underground Mining, Australian Centre for Geomechanics, Perth, pp. 367-381.

Guest, A \& Read, J 2009, 'Geotechnical model', in J Read \& P Stacey (eds), Guidelines for Open Pit Slope Design, CSIRO Publishing, Collingwood, pp. 201-212.

Hustrulid, WA, McCarter, MK, \& van Zyl, DJA 2001, Slope Stability in Surface Mining, Society for Mining, Metallurgy and Exploration, Littleton.

Hadjigeorgiou, J \& Harrison, JP 2011, 'Uncertainty and sources of error in rock engineering', in Q Qian \& X Zhou (eds), Proceedings of the 12th ISRM International Congress on Rock Mechanics: Harmonising Rock Engineering and the Environment, CRC Press, Leiden, pp. 2063-2067.

Hadjigeorgiou, J 2012, 'Where do the data come from?', in Y Potvin (ed.), Proceedings of the Sixth International Seminar on Deep and High Stress Mining, Australian Centre for Geomechanics, Perth, pp. 259-277.

Haile, A 2004, 'A reporting framework for geotechnical classification of mining projects, Aus/MM Bulletin, September/October 2004, $\mathrm{pp}, 30-37$.

Hoek, E 1994, 'The challenge of input data for rock engineering', letter to the editor, ISRM News Journal, vol. 2, no. 2, pp. 23-24.

Itasca International, Inc. 2019a, FLAC3D, computer software, Itasca International, Inc., Minneapolis, https://www.itascacg.com/ software/flac3d

Itasca International, Inc. 2019b, 3DEC, computer software, Itasca International, Inc., Minneapolis, https://www.itascacg.com/ software/3dec

Jefferies, M, Lorig L \& Alvarez, C 2008, 'Influence of rock strength spatial variability on slope stability', in R Hart, C Detournay \& P Cundall (eds), Proceedings of the First International FLAC/DEM Symposium on Numerical Modelling, Itasca International, Inc., Minneapolis.

Kim, YC, Cassun, WC \& Hall, TE 1976, Pit Slope Manual Supplement 5-3: Financial Computer Programs, Canada Department of Energy, Mines and Resources, https://doi.org/10.4095/307102

Lai, FJ, Bamford, WE, Yuen, STS \& Li, T 2009, 'Implementing value at risk in slope risk evaluation', Proceedings of the Third International Symposium on Rock Slope Stability in Open Pit Mining and Civil Engineering, Universidad de los Andes, Santiago.

Lilly, PA 2006, 'Geotechnical risk considerations in mine planning', in R Dimitrakopoulus (ed.), Orebody Modelling and Strategic Mine Planning - Uncertainty and Risk Management Models, Spectrum Series no. 14, The Australasian Institute of Mining and Metallurgy, Melbourne.

Lorig, LJ 2009, 'Challenges in current slope stability analysis methods', Proceedings of the Third International Symposium on Rock Slope Stability in Open Pit Mining and Civil Engineering, Universidad de los Andes, Santiago.

Lorig, L, Stacey, P \& Read, J 2009, 'Slope design methods', in J Read \& P Stacey (eds), Guidelines for Open Pit Slope Design, CSIRO Publishing, Collingwood, pp. 237-264.

McMahon, BK 1985, Geotechnical Design in the Face of Uncertainty: EH Davis Memorial Lecture, Australian Geomechanics Society, Barton.

Read, JRL 1994, 'Risk analysis and uncertainty in open pit mine design', Proceedings of the 4th Large Open Pit Conference, The Australian Institute of Mining and Metallurgy, Melbourne, pp. 139-143.

Read, J 2009a, 'Structural model', in J Read \& P Stacey (eds), Guidelines for Open Pit Slope Design, CSIRO Publishing, Collingwood, pp. 69-82.

Read, J 2009b, 'Acceptance criteria', in J Read \& P Stacey (eds), Guidelines for Open Pit Slope Design, CSIRO Publishing, Collingwood, pp. 221-236.

Read, J 2009c, 'Data uncertainy', in J Read \& P Stacey (eds), Guidelines for Open Pit Slope Design, CSIRO Publishing, Collingwood, pp. 213-220.

Read, J \& Stacey, P, 2009, Guidelines for Open Pit Slope Design, CSIRO Publishing, Collingwood.

Stacey, P 2009, 'Fundamentals of slope design', in J Read \& P Stacey (eds), Guidelines for Open Pit Slope Design, CSIRO Publishing, Collingwood, pp. 1-14.

Steffen, OKH 1997, 'Planning of open pit mines on risk basis', Journal of The Southern African Institute of Mining and Metallurgy, vol. 2, pp. 47-56.

Swindels, CF 1990, 'Geotechnical studies for open pit mines - West Australian operating experience', Proceedings of the Mine Geologists Conference, The Australian Institute of Mining and Metallurgy, Melbourne, pp. 160-170. 